\title{
FREE RADICALS IN ISCHEMIC MYOCARDIAL INJURY
}

\author{
Steven W. Werns, M.D.*, Michael J. Shea, M.D., ${ }^{*}$ and Benedict R. Lucchesi, M.D., Ph.D. $\dagger$ \\ Departments of *Internal Medicine (Division of Cardiology) and +Pharmacology \\ The University of Michigan Medicine School, Ann Arbor, Michigan 48109, U.S.A.
}

(Received 23 January 1985; Revised 11 March 1985: Accepted 12 March 1985)

\begin{abstract}
Myocardial ischemia causes release of chemotactic factors, migration of neutrophils, peroxidation of lipids, and depletion of free radical scavengers. The invading neutrophils may injure the myocardial vasculature and sarcolemma by generating oxygen free radicals. Several agents that affect neutrophils or oxygen radicals were evaluated in a canine model of regional myocardial ischemia and reperfusion. Anesthetized dogs underwent occlusion and reperfusion of the left circumflex coronary artery. Infarct zone, area at risk of infarction, and total left ventricle were quantified by gravimetric and planimetric analysis. Limitation of infarct size by ibuprofen was associated with marked suppression of leukocyte accumulation within the ischemic myocardium. Neutrophil depletion by antiserum resulted in similar reductions of infarct size and was accompanied by a reduction in leukocyte infiltration. A combination of oxygen radical scavengers, superoxide dismutase plus catalase, decreased myocardial injury whether infusion began before occlusion or $75 \mathrm{~min}$ after occlusion. None of the treatments significantly altered hemodynamic indices of myocardial oxygen demand. Reduction of infarct size by ibuprofen, neutrophil antiserum, and free radical scavengers indicates that neutrophils and oxygen radicals participate in producing the irreversible damage to the myocardium during ischemia and reperfusion.
\end{abstract}

Keywords-Superoxide dismutase, Catalase, Reperfusion injury, Myocardial ischemia, Polymorphonuclear neutrophils, Oxygen free radicals, Free radical scavengers, Ibuprofen

\section{INTRODUCTION}

Prognosis after myocardial infarction (MI) is directly related to the extent of irreversible ischemic injury and consequently, many interventions designed to reduce ultimate infarct size have been explored. ${ }^{1}$ Experimentally, infarct size varies directly with the duration of coronary occlusion. ${ }^{2}$ Therefore, the angiographic documentation of coronary artery thrombosis during evolving MI suggested that thrombolytic therapy might prove useful to limit the extent of ultimate injury. ${ }^{3}$ Clinical trials of intracoronary administration of streptokinase during MI have demonstrated coronary recanalization in up to $80 \%$ of patients treated within several hours of symptom onset. ${ }^{4}$ Several of the trials, however, have failed to show any improvement in survival or left ventricular function..$^{5.6}$ Although the lack of benefit has been attributed to a diminishing value of reperfusion

Address for Correspondence-Benedict R. Lucchesi, M.D., Ph.D., Department of Pharmacology. M6322 Medical Science Bldg. I. The University of Michigan Medical School. Ann Arbor. MI 48109. U.S.A. with increasing delay between symptom onset and flow restoration, ${ }^{7,8}$ the disappointing results may reflect the deleterious effects of oxygen free radicals on the reperfused ischemic tissue.

Early concerns about reperfusion injury focused on the observation of intramyocardial hemorrhage after reperfusion, and possible extension of myocardial necrosis, ${ }^{2}$ but subsequent studies concluded that hemorrhage does not extend necrosis. ${ }^{9}$ Other experiments have delineated an inflammatory response to ischemia that may be facilitated by reperfusion. Activation of the complement system, ${ }^{10,11}$ generation of chemotactic factors, ${ }^{12}$ migration of neutrophils, ${ }^{13}$ peroxidation of lipids, ${ }^{14}$ and depletion of intracellular free radical scavengers, ${ }^{14.15}$ are the key components of the inflammatory process that are triggered during myocardial ischemia. Recent studies with agents that lower circulating neutrophil counts ${ }^{13.16}$ and enzymes that interact with activated oxygen species ${ }^{17-19}$ illustrate the basis for our interest in oxygen free radicals as mediators of myocardial ischemic injury. This review outlines the growing number of studies relating free radicals to the ul- 
timate extent of damage after myocardial ischemia and reperfusion.

\section{MATERIALS AND METHODS}

Occlusion-reperfusion model of myocardial infarction

Detailed methods have been presented in previous publications. ${ }^{20}$ Male mongrel dogs $(12-15 \mathrm{~kg})$ were anesthetized with sodium pentobarbital ( $30 \mathrm{mg} / \mathrm{kg}$ i.v.), intubated, and ventilated with room air using a Harvard respirator. Catheters were inserted in the left jugular vein and left carotid artery. After a left thoracotomy, the heart was suspended in a pericardial cradle and the left circumflex coronary artery ( $\mathrm{LCX}$ ) was isolated distal to the atrial branch and proximal to major ventricular branches. Coronary blood flow was recorded with an electromagnetic flow probe and flowmeter (Carolina Instruments, Inc.). The arterial pressure was measured with a Statham P23Db pressure transducer calibrated against a mercury manometer. Arterial pressure, LCX blood flow, and the lead II electrocardiogram were recorded continuously on a Grass model 7 polygraph.

To limit reperfusion arrhythmias and myocardial hemorrhage, a critical stenosis was placed on the LCX which reduced the hyperemic response to a 10 -s occlusion without altering basal LCX flow. LCX occlusion was maintained for 60 or $90 \mathrm{~min}$ and then gradually released over $30 \mathrm{~min}$. Dogs remained anesthetized until sacrifice by electrical fibrillation $6 \mathrm{~h}$ after reperfusion, or until closure of the thoracotomy in studies that were terminated $24 \mathrm{~h}$ after reperfusion.

\section{Post mortem quantification of infarct size}

Cannulas were inserted in the aorta above the coronary ostia and the LCX just distal to the site of occlusion. The aorta was perfused in a retrograde manner with $0.5 \%$ Evans blue dye and the LCX was perfused with $1.5 \%$ triphenyltetrazolium chloride (TTC) in 20 $\mathrm{mM}$ potassium phosphate buffer $\left(\mathrm{pH} 7.4,37^{\circ} \mathrm{C}\right)$. The solutions were infused simultaneously for $5 \mathrm{~min}$ at 100 $\mathrm{mm} \mathrm{Hg}$ with the heart suspended in a water bath $\left(37^{\circ} \mathrm{C}\right)$. The stained heart was cut from apex to base into $1 \mathrm{~cm}$ thick transverse sections. Ventricular sections were traced onto clear plastic overlays for planimetric analysis of infarct size prior to dissection for gravimetric analysis. The area of the left ventricle at risk of infarction due to dependence on the LCX was demarcated by the lack of Evans blue dye. The infarct zone within the risk area was identified by lack of staining by the red formazan dye derived from reduction of TTC by dehydrogenase enzymes present in viable myocardium and absent from necrotic myocardium. ${ }^{2 !}$ Infarct size was calculated both as a percentage of the area at risk and total left ventricle. A blinded investigator confirmed the presence or absence of necrosis in tissue sections examined under light microscopy.

\section{Isotope labeling of autologous leukocytes}

Autologous leukocytes were harvested from $50 \mathrm{ml}$ of heparinized venous blood by incubation with $3.0 \mathrm{ml}$ of hydroxyethyl starch $(6 \%$ Volex. McGaw Laboratories, Inc.). The leukocytes were labeled with indium111 by incubation with $500 \mu \mathrm{Ci}$ of indium-111 oxine. Labeled cells $(300-450 \mu \mathrm{Ci})$ were injected intravenously $1 \mathrm{~h}$ before LCX occlusion. Tissue radioactivity was assayed with a Packard 5320 gamma spectrometer.

\section{RESULTS}

Effect of ibuprofen on size and leukocyte accumulation of experimental MI

Although numerous studies have demonstrated that ibuprofen reduces experimental infarct size, its beneficial effects were not accompanied by salutory changes in myocardial oxygen supply or demand. ${ }^{20}$ Therefore, experiments were performed to determine whether ibuprofen salvages ischemic myocardium by suppressing platelet or polymorphonuclear leukocyte (PMN) accumulation within ischemic tissue. ${ }^{22}$ This was accomplished by administration of autologous platelets or leukocytes labeled with indium-111 prior to coronary occlusion, and post mortem determination of tissue radioactivity by gamma spectrometry. Counts were normalized for tissue weight, and then expressed as platelet or PMN accumulation ratios of ischemic to nonischemic samples. To control for the cardioprotective effect of ibuprofen, tissue sections from control and drug-treated dogs with equal amounts of injury (i.e., grams of infarcted tissue) were compared. The treatment group received 6 doses of ibuprofen, $12.5 \mathrm{mg} / \mathrm{kg}$ intravenously, every $4 \mathrm{~h}$ beginning $30 \mathrm{~min}$ before coronary occlusion.

As previously shown, ${ }^{20}$ this dosage regimen resulted in a $40 \%$ reduction of infarct size expressed as a percentage of the area at risk of infarction (Fig. 1). The decrease in infarct size was accompanied by marked suppression of PMN accumulation in infarcted myocardium. The greatest difference between control and treated dogs was observed when tissue sections with greater than $1 \mathrm{~g}$ of infarct were compared, in which PMN accumulation was $64 \%$ less in ibuprofen treated animals. Platelet accumulation, however, was unaffected by ibuprofen treatment, with platelet accumu- 
IBUPROFEN - INFARCT SIZE

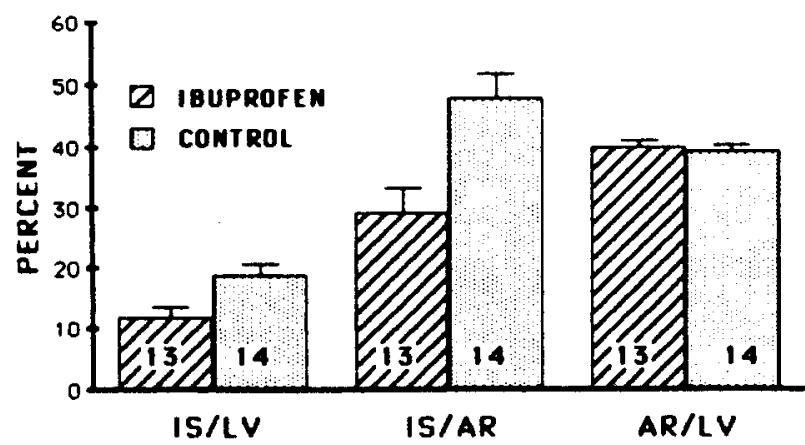

Fig. 1. Effect of ibuprofen on canine infarct size after a 60-min occlusion and 24-h reperfusion of the left circumflex coronary artery. Infarct size expressed both as percentage of the left ventricle and percentage of the area at risk was significantly smaller for the ibuprofen group $(p=0.005)$. (Data expressed as mean \pm 1 SEM: IS = infarct size: $L V=$ left ventricle; $A R=$ area at risk.)

lation ratios up to 20 in both control and treated animals. Autoradiography of transverse myocardial sections confirmed that the radiolabeled cells localized primarily within the boundaries of the infarcted myocardium.

These results suggest that the inhibitory action of ibuprofen on platelet aggregation was not responsible for the observed limitation of infarct size. The suppression of PMN accumulation, however, might protect ischemic myocardium from the cytotoxic effects of oxygen free radicals and lysosomal enzymes released by stimulated neutrophils. Therefore, a subsequent series of experiments was designed to further evaluate the role of neutrophils in evolving myocardial infarction.

\section{Reduction of ischemic myocardial injury by neutrophil depletion}

Dogs were depleted of circulating neutrophils (PMN) by intravenous administration of rabbit antiserum to canine PMNs prior to LCX occlusion for $90 \mathrm{~min}$ and reperfusion for $6 \mathrm{~h} .{ }^{16}$ The antiserum achieved a $77 \%$ reduction in circulating PMN. Assessment of infarct size as a percentage of the area at risk revealed a $43 \%$ reduction by neutrophil depletion (Fig. 2). Histologic analysis of the infarcts revealed only rare PMN in ischemic zone myocardial sections from dogs treated with antiserum, in contrast to an abundant PMN accumulation in control infarcts. There were no hemodynamic differences between the control and treatment groups. Therefore, the reduction of infarct size by depletion of PMN supports the conclusion that accumulation of PMN in ischemic-reperfused myocardial tissue is an important determinant of the ultimate extent of tissue necrosis due to ischemic myocardial injury.
NEUTROPHIL ANTISERUM - INFARCT SIZE

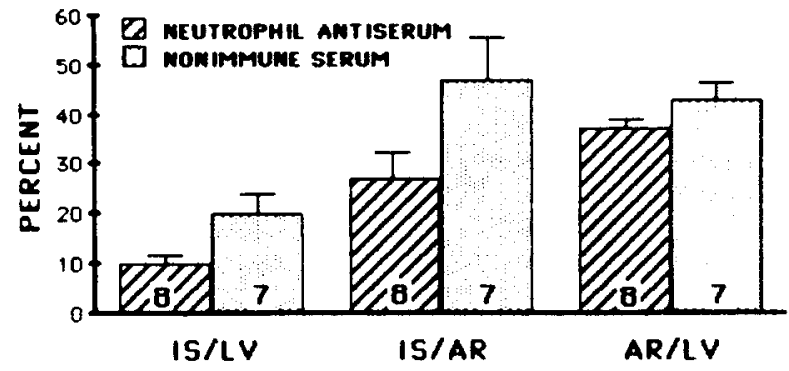

Fig. 2. Effect of neutrophil antiserum on canine infarct size after a 90 -min occlusion and 6-h reperfusion of the left circumflex coronary artery. Infarct size was significantly smaller for the neutrophil antiserum group $(p<0.05)$.

\section{Reduction of ischemic myocardial injury by superoxide dismutase plus catalase}

The previous studies demonstrated that PMN play a significant role in the ultimate extent of ischemic myocardial injury. Because stimulated PMN may damage tissue by release of oxygen free radicals, we evaluated the effect of oxygen radical scavengers on infarct size in the canine model of regional ischemia and reperfusion. ${ }^{19}$ Treatment consisted of a combination of superoxide dismutase (SOD) $(5 \mathrm{mg} / \mathrm{kg}[2900 \mathrm{U} / \mathrm{mg}$, Sigma]) plus catalase (CAT) $(5 \mathrm{mg} / \mathrm{kg}[11,000 \mathrm{U} / \mathrm{mg}$, Sigma]) infused via the left atrium. A 2-h infusion starting 15 min before and ending $15 \mathrm{~min}$ after the $90-\mathrm{min}$ LCX occlusion was associated with infarcts that were 19\% of the area at risk, compared to $44 \%$ in controls $(p<.05)$. SOD plus CAT was equally effective in a group treated for $1 \mathrm{~h}$ starting $15 \mathrm{~min}$ before reperfusion, but ineffective when the combined infusion commenced $40 \mathrm{~min}$ after reperfusion (Fig. 3). The findings strengthen the proposition that oxygen metabolites are involved in tissue injury and also indicate that preventable damage occurs during early reperfusion as oxygenation is restored to previously ischemic tissue. Experiments to assess the individual effects of SOD and CAT are now in progress and suggest that SOD alone is equally as effective as the combined treatment regimen.

\section{Effect of lipoxygenase inhibition on ischemic myocardial injury}

Based on the preceding studies, it was postulated that inhibition of the 5-lipoxygenase enzyme might reduce ischemic myocardial injury by preventing formation of leukotriene B4, a potent chemotactic factor 
SOD/CAT - INFARCT SIZE

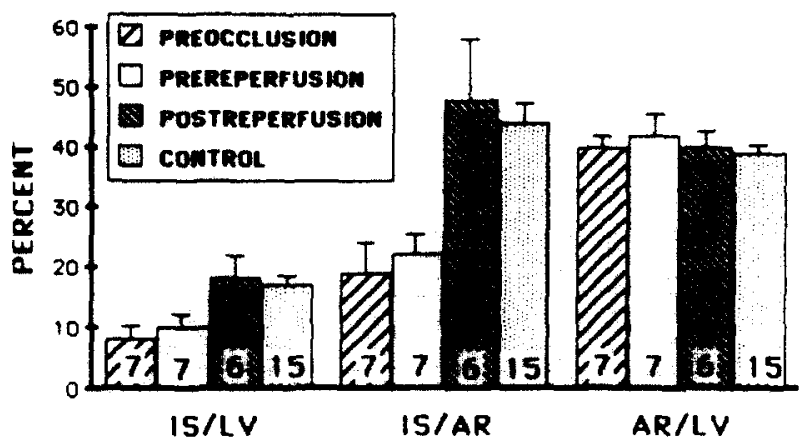

Fig. 3. Effect of superoxide dismutase plus catalase on canine infarct size after a 90 -min occlusion and 24-h reperfusion of the left circumflex coronary artery. In preocclusion group, SOD plus CAT was administered as an infusion via the left atrium beginning $15 \mathrm{~min}$ before occlusion and ending $15 \mathrm{~min}$ after reperfusion. The prereperfusion group's infusion began $15 \mathrm{~min}$ before reperfusion and ended 45 min after reperfusion. The postreperfusion group's infusion began $40 \mathrm{~min}$ after and ended $100 \mathrm{~min}$ after reperfusion. By analysis of variance and Duncan's multiple range test, infarct size for the preocclusion and prereperfusion groups was significantly smaller than for the control group $(p<0.05)$

for neutrophils ${ }^{23}$ produced via the lipoxygenase pathway of arachidonic acid metabolism. ${ }^{24}$ Therefore, several drugs with antilipoxygenase activity have been investigated. Nafazatrom (BAYg6575) is a substituted pyrazole compound that displays several actions. In addition to inhibiting lipoxygenase, it inhibits the major catabolic enzyme of prostacyclin and has direct freeradical scavenging activity. BW755C, a novel non-steroidal antiinflammatory agent, is a dual inhibitor of both the lipoxygenase and cyclooxygenase pathways of arachidonic acid metabolism. Benoxaprofen, another antiinflammatory drug, is a lipoxygenase inhibitor exerting weak inhibition of cyclooxygenase. Each of the three agents produced a 50\% reduction in infarct size as a percentage of the area at risk in our canine model of regional ischemia and reperfusion (Figs. 4-6). ${ }^{25.26}$ The myocardial sparing effects could not be attributed to alterations in hemodynamic determinants of myocardial oxygen demand. In a similar study by Mullane et al. ${ }^{13} \mathrm{BW} 755 \mathrm{C}$ was equally as effective when administered $30 \mathrm{~min}$ after reperfusion, which excludes the possibility that myocardial protection was secondary to effects on myocardial oxygen supply or demand during ischemia. The same group also reported evidence that both BW755C and nafazatrom attenuate neutrophil infiltration of ischemic myocardium, suggesting that the drugs may salvage ischemic myocardium by suppressing synthesis of lipoxygenase products such as leukotriene B4, which act as neutrophil chemoattractants. ${ }^{13.27}$

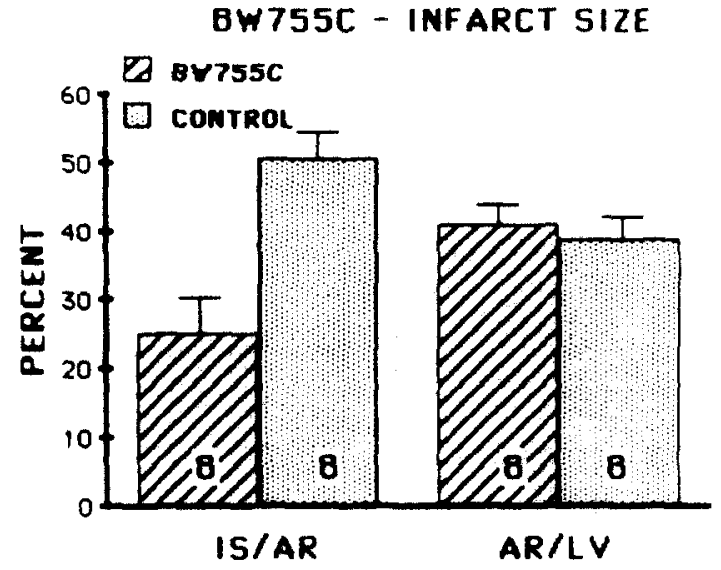

Fig. 4. Effect of BW755C on canine infarct size after a 90min occlusion and $24-h$ reperfusion of the left circumflex coronary artery. Treatment with BW755C $10 \mathrm{mg} / \mathrm{kg}$, i.v. 30 min before occlusion significantly reduced infarct size $(p<0.05)$.

\section{DISCUSSION}

There is a growing body of evidence that the effects of oxygen free radicals are a major component of the myocardial injury caused by ischemia and reperfusion. Utilizing either a xanthine oxidase system or activated neutrophils to generate oxygen radicals, several laboratories have demonstrated the toxic effects of free radicals on vascular endothelium, ${ }^{28}$ myocardial mitochondria, ${ }^{29}$ and sarcoplasmic reticulum. ${ }^{30}$ Free radicals may also intensify the tissue inflammatory response by generating a neutrophil chemotactic factor from plasma components. ${ }^{31}$ The susceptibility of the myocardium to free radical damage is probably enhanced by depletion of intracellular radical scavengers during ischemia and reperfusion. ${ }^{14.15}$

Free radicals may arise in ischemic myocardium from several sources (Fig. 7) ${ }^{32}$ Mitochondria isolated from

NAFAZATROM - INFARCT SIZE

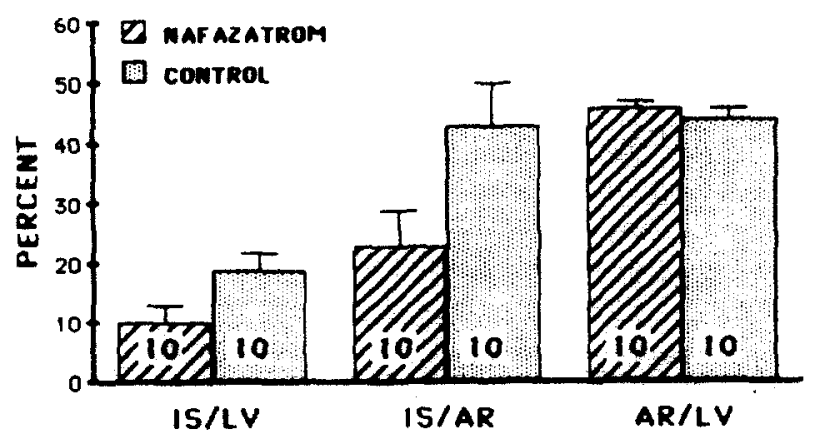

Fig. 5. Effect of nafazatrom on canine infarct size after a 90-min occlusion and 24-h reperfusion of the left circumflex coronary artery. Treatment with nafazatrom $1 \mathrm{mg} / \mathrm{kg}$ i.v. every $6 \mathrm{~h}$ for $48 \mathrm{~h}$ starting $24 \mathrm{~h}$ before occlusion significantly reduced infarct size $(p<0.05)$. 
BEMOXAPROFEN - IMFARCT SIZE

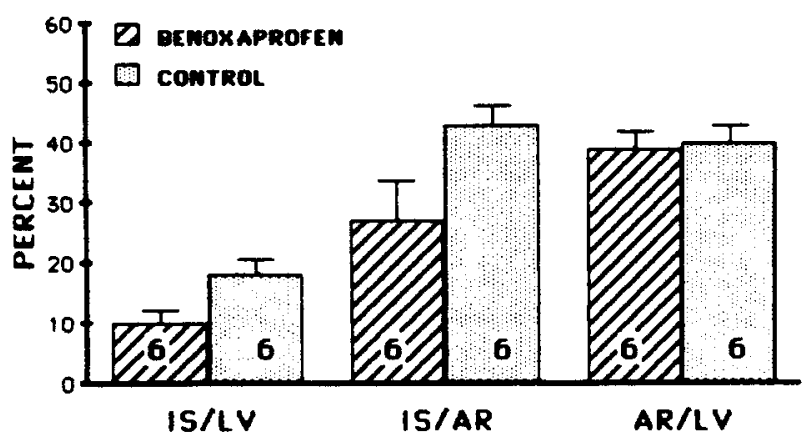

Fig. 6. Effect of benoxaprofen on canine infarct size after a 90-min occlusion and 24-h reperfusion of the left circumflex coronary artery. Treatment with benoxaprofen $30 \mathrm{mg} / \mathrm{kg}$ per d orally for $3 \mathrm{~d}$ starting $2 \mathrm{~d}$ before surgery significantly reduced infarct size.

ischemic myocardium manifest increased radical production and decreased ATP generation after reoxygenation that is prevented by radical scavengers. ${ }^{33}$ As free arachidonic acid accumulates in ischemic myocardium,${ }^{34}$ enhanced prostaglandin synthesis would be ac- companied by increased formation of free radicals. ${ }^{35}$ During ischemia, xanthine dehydrogenase is converted to xanthine oxidase $e^{32}$ and ATP is catabolyzed to hypoxanthine and xanthine. ${ }^{36}$ As the latter is converted to uric acid by xanthine oxidase, superoxide anion, hydrogen peroxide, and hydroxyl radical production would result. ${ }^{37}$ Finally, myocardial ischemia triggers complement activation, ${ }^{10.11}$ chemotactic factor generation, ${ }^{12}$ and neutrophil migration. ${ }^{13}$ This would give rise to the release of free radicals within the myocardium by activated neutrophils and macrophages. ${ }^{38,39}$

Although direct measurement of free radicals in vivo is not technically feasible, the indirect evidence that free radicals mediate damage during myocardial ischemia and reperfusion is strong. Preliminary studies have shown that myocardial ischemia in both animals and humans is accompanied by release of lipid peroxidation products that may reflect free-radical induced membrane damage. ${ }^{14}$ Our results with SOD plus CAT are consistent with several postulated mechanisms of injury by free radicals during ischemia and reperfusion. One possibility is that oxygen metabolites may have a direct cytotoxicity that is ameliorated by SOD plus CAT

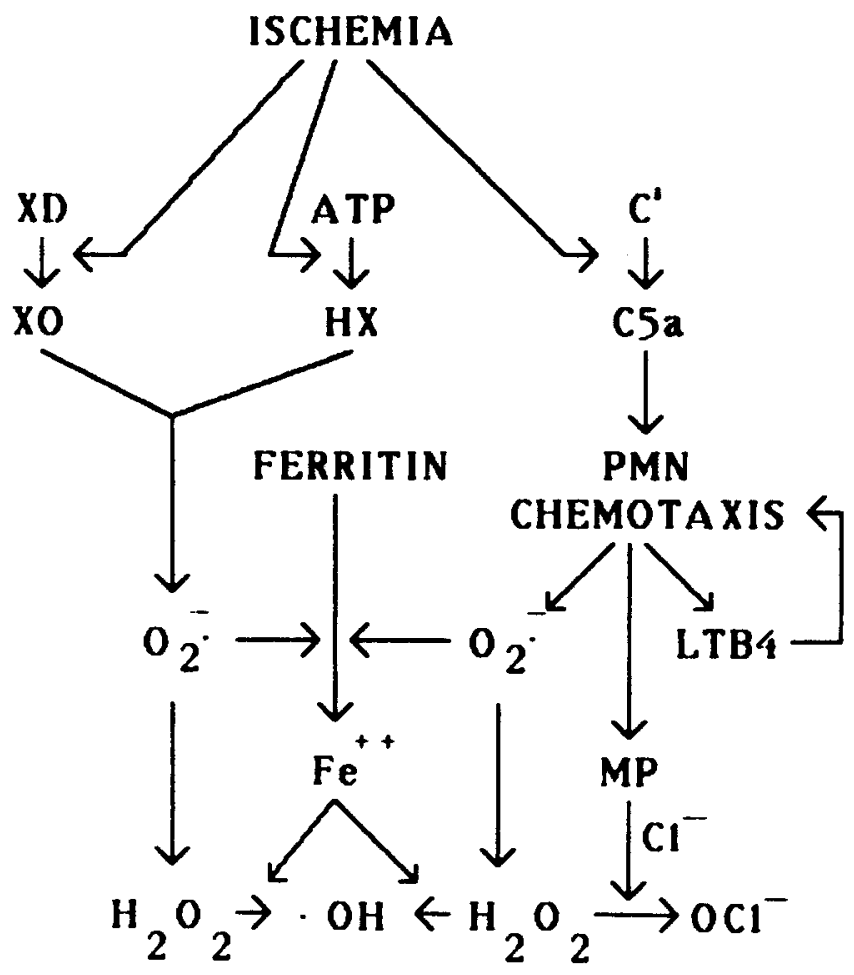

Fig. 7. Sources of oxygen radicals within ischemic myocardium. Myocardium ischemia causes formation of xanthine oxidase (XO) from xanthine dehydrogenase (XD), hypoxanthine (HX) from adenosine triphosphate (ATP), and $\mathrm{C}_{2}$, via the complement cascade $(\mathrm{C})$. Superoxide anion $\left(\mathrm{O}_{2}^{\circ}\right)$ arises when $\mathrm{XO}$ oxidizes $\mathrm{HX}$ and $\mathrm{C5}$, activates the polymorphonuclear neutrophil (PMN). $\mathrm{O}_{2}^{-}$releases ferrous ions $\left(\mathrm{Fe}^{++}\right)$from ferritin and is converted to hydrogen peroxide $\left(\mathrm{H}_{2} \mathrm{O}_{2}\right)$ by superoxide dismutase. The $\mathrm{Fe}^{++}$catalyzes reduction of $\mathrm{H}_{2} \mathrm{O}$ to hydroxyl radical ( $\left.\cdot \mathrm{OH}\right)$. Myeloperoxidase (MP) released by PMNs catalyzes the reaction of $\mathrm{H}_{2} \mathrm{O}_{2}$ with chloride $\left(\mathrm{Cl}^{-}\right)$to form hypochlorite anion $\left(\mathrm{OCl}^{-}\right)$. PMNs also release leukotriene B4 (LTB4), a chemotactic factor for PMNs. 
by reacting with superoxide anion and hydrogen peroxide before they can be converted to more reactive species such as hydroxyl radical ${ }^{40}$ or $N$-chloramines. ${ }^{+1}$ SOD may also curtail iron-catalyzed formation of hydroxyl radical by preventing mobilization of iron from ferritin by phagocyte-derived superoxide anion. ${ }^{+2} \mathrm{An}$ indirect route of radical-mediated injury may be through the chemoattraction of neutrophils to the myocardium by products of lipid peroxidation. ${ }^{31.43}$ SOD could attenuate neutrophil infiltration of ischemic tissue by suppressing superoxide-induced peroxidation. A third possibility is that SOD plus CAT favorably alters prostaglandin metabolism within the ischemic environment. SOD, for example, has been shown to inhibit prostaglandin formation by phagocytic neutrophils, ${ }^{44}$ and catalase inhibits prostacyclin release from vascular endothelium exposed to stimulated neutrophils. ${ }^{+5}$

The conclusions of multiple studies merit reexamination in light of the newly recognized role of free radicals in ischemic myocardial injury. The varying effects on infarct size of drugs that inhibit cyclooxygenase seems to be correlated with their differential effects on neutrophil function. For example, ibuprofen reduces infarct size and neutrophil superoxide anion production, while aspirin does neither, despite its ability to inhibit cyclooxygenase. ${ }^{46.47}$ Prostacyclin protects ischemic myocardium in the absence of significant effects on myocardial $\mathrm{O}_{2}$ demand or regional myocardial blood flow. ${ }^{48}$ Prostacyclin's inhibitory influence on oxygen radical release by neutrophils, however, may be responsible for its cytoprotective property. ${ }^{+4}$ Allopurinol's antiischemic characteristics have been ascribed to preservation of a purine pool for ATP synthesis, ${ }^{51}$ but may actually reflect inhibition of oxygen radical generation by myocardial ${ }^{51}$ xanthine oxidase. Infarct size reduction by mannitol was considered an osmolar effect on cell swelling, ${ }^{2}$ but quenching of hydroxyl radicals may be its true mode of action. 52

The major hypothesis that we have attempted to develop is that inflammatory leukocytes in acute reactions associated with reperfusion of the ischemic myocardium liberate cytotoxic products into the surrounding environment, thereby leading to an extension of the irreversible cellular injury beyond that due to the ischemic process alone. In addition to undergoing a "respiratory burst" that is characterized by an increase in oxygen consumption and the production of cytotoxic activated oxygen species, the leukocytes also release preformed proteases from cytoplasmic lysosomal granules. The proteases within the azurophil cytoplasmic granules are elastase, cathepsin $\mathbf{G}$, and an unspecified serine protease, all of which are active at neutral $\mathrm{pH}$. In addition, a specific-granule collagenase contributes to the leukocyte mediated tissue injury. There is, how- ever, a regulatory mechanism whereby the extent of the inflammatory responses is kept under control. The most significant controlling mechanism is through the action of an $\alpha-1$-proteinase inhibitor $(\alpha-1-\mathrm{PI})$ which is present in tissues and is derived from the circulation as a result of transudation of plasma proteins. ${ }^{3}$ The primary physiologic role of $\alpha-1-\mathrm{PI}$ is to inhibit the elastase released from active or dying PMNs. A second inhibitor in plasma is $\alpha$-1-antichymotrypsin ( $\alpha-1-\mathrm{ACHY})$ and also serves as a regulator of the acute phase reaction. An important protective function of $\alpha-1-\mathrm{ACHY}$ may be to inhibit PMN cathepsin G. Thus, $\alpha-1-\mathrm{PI}$ and $\alpha-1$-ACHY serve as important modulators of the acute as well as the chronic inflammatory response to tissue injury, thus limiting the ultimate extent of the leukocyte mediated and macrophage mediated cytotoxicity. The formation and release of activated oxygen species and oxygen free radicals can inactivate the plasma derived proteinase inhibitors; a reaction that can be prevented by superoxide dismutase and catalase.

The oxygen-derived free radicals and activated oxygen species can also influence the inflammatory response by inactivating chemotactic substances that serve to attract PMNs and monocytes to regions of tissue injury, thereby providing an important feedback mechanism for self-regulation of the leukocyte chemotactic response.

Oxygen free radicals and other reactive species of oxygen can directly alter tissue macromolecules such as collagen and can depolymerize hyaluronic acid thus making it more susceptible to degradation by $\beta-N$-acetylglucosamidase. ${ }^{54}$ Scavengers of oxygen free radicals can protect against the deleterious effects of reactive oxygen species upon tissue macromolecules.$^{54.55}$

It is apparent that PMN derived oxidants at sites of tissue injury can alter the balance between leukocyte released proteases and plasma derived proteinase inhibitors as well as limit the action of chemotactic mediators and to disrupt extracellular supportive macromolecular proteins. These events, taken together, influence the degree and extent of progression of the tissue response to injury. The ability to modify one or more of the actions of oxygen free radicals through the use of free radical scavengers should result in limiting the extent to which tissue undergoes irreversible injury.

The traditional approaches to limitation of experimental infarct size have revolved around the concept of an imbalance between myocardial oxygen supply and demand. Therefore, interventions that increase oxygen availability or reduce oxygen requirements have been a primary focus of laboratory investigations. The expanding clinical use of thrombolytic therapy in acute myocardial infarction dramatizes the potential clinical applications of basic research. ${ }^{56}$ We believe, however. 
that implementation of this new mode of therapy confers a mixed blessing, in that reperfusion of ischemic tissue may accelerate the generation of oxygen-derived free radicals. Pretreatment with a free radical scavenger. however, might significantly increase the benefit of reperfusion and result in greater myocardial salvage. We eagerly await clinical evaluation of free radical scavengers in patients with acute myocardial infarction in order to address this important therapeutic question.

Acknowledgements - This study was supported by the National Institutes of Health. Heart, Lung and Blood Institute. Grant \# 1978206 and by a grant-in-aid from the American Heart Association of Michigan.

Dr. Werns is the recipient of a Physician Scientist Award from the National Institutes of Health, Heart, Lung and Blood Institute. Grant \# HL-01409-01 and is a Merck Fellow of the American College of Cardiology. Dr. Shea is a Clinician-Scientist Awardee of the American Heart Association.

\section{REFERENCES}

1. R. E. Rude. J. E. Muller and E. Braunwald. Efforts to limit the size of myocardial infarcts. Ann. Int. Med. 95: 736-76) (1981).

2. R. A. Kloner and E. Braunwald. Observations on experimental myocardial ischemia. Cardiovasc. Res. 14: 37I-395 (1980).

3. M. A. DeWood. J. Spores, G. R. Hensley. C. S. Simpson. G. S. Evaster, K. I. Sutherland. R. P. Grunwald, and J. P. Shields. Coronary arteriographic findings in acute transmural myocardial infarction. Circulation 68(Suppl. I): I-39-I-49 (1983).

4. C. D. Furberg. Clinical value of intracoronary streptokinase. Am. J. Cardiol. 53: 626-627 (1984).

5. F. Khaja. J. A. Walton. J. F. Brymer. E. Lo. L. Osterberger. W. W. O'Neill. H. T. Colfer. R. Weiss. T. Lee. T. Kurian. A D. Goldberg. B. Pitt, and S. Goldstein. Intracoronary fibrinolytic therapy in acute myocardial infarction. N. Engl. J. Med. 308: 1305-1311 (1983).

6. R. H. Leiboff, R. J. Katz, A. G. Wasserman. G. B. Bren, H. Schwartz. P. J. Varghese, and A. M. Ross. A randomized. angiographically controlled trial of intracoronary streptokinase in acute myocardial infarction. Am. J. Cardiol. 53: 404-407 (1984).

7. F. Schwarz. G. Schuler. H. Katus. M. Hofmann. J. Manthey. H. Tillmanns. H. C. Mehmel, and W. Kubler. Intracoronary thrombolysis in acute myocardial infarction: Duration of ischemia as a major determinant of late results after recanalization. Am. J. Cardiol. 50: 933-937 (1982).

8. H. J. C. Swan. Thrombolysis in acute evolving myocardial infarction. N. Engl. J. Med. 308: 1354-1.355 (1983).

9. R. A. Kloner. S. G. Ellis. R. Lange. and E. Braunwald. Studies of experimental coronary artery reperfusion. Circulation 68 (Suppl. I): I-8-I-15 (1983)

10. R. N. Pinckard. M. S. Olson. P. C. Giclas. R. Terry. J. T. Boyer. and $\mathbf{R}$. A. O'Rourke. Consumption of classical complement components by heart subcellular membranes in vitro and in patients after acute myocardial infarction. J. Clin. Imest. 56: $740-750$ (1975).

II. R. N. Pinckard. R. A. O Rourke. M. H. Crawford. F. S. Grover. L. M. McManus. J. J. Ghidoni. S. B. Storrs. and M. S. Olson. Complement localization and mediation of ischemic injury in baboon myocardium. J. Clin. Imest. 66: 1050-1056 (1980).

12. J. R. Hartmann. J. A. Robinson. and R. M. Gunnar. Chemotactic activity in the coronary sinus after experimental myocardial infarction: Effects of pharmacologic interventions on ischemic injury. Am. J. Cardiol 40: 550-555 (1977).

13. K. M. Mullane. N. Read. J. A. Salmon. and S. Moncada. Role of leukocytes in acute myocardial infarction in anesthetized dogs: Relationship to myocardial salvage by antiinflammatory drugs. J. Pharmacol. Exp. Ther. 228: 510-522 (1984).

14. P. S. Rao and H. S. Mueller. Lipid peroxidation and acute myocardial ischemia. Adv. Exp. Med. Biol. 161: 347-363 (1983).

15. C. Thiemermann, E. Steinhagen-Thiessen, and K. Schor. Inhibition of oxygen-centered frec radical formation by the stable prostacyclin-mimetic iloprost (ZK36374) in acute myocardial ischemia. J. Cardiovasc. Pharmacol. 6: 356-366 (1984).

16. J. L. Romson, B. G. Hook, S. L. Kunkel, G. D. Abrams. M. A. Schork, and B. R. Lucchesi. Reduction of the extent of ischemic myocardial injury by neutrophil depletion in the dog. Circulation 67: 1016-1023 (1983).

17. S. W. Werns, M. J. Shea. E. M. Driscoll, C. Cohen, G. D. Abrams. B. Pitt. and B. R. Lucchesi. The independent effects of oxygen radical scavengers on canine infarct size: Reduction by superoxide dismutase but not catalase. Circ. Res. 56: 895898 (1985).

18. M. Shlafer. P. F. Kane. V. Y. Wiggins, and M. M. Kirsh. Possible role for cytotoxic oxygen metabolites in the pathogenesis of cardiac ischemic injury. Circulation 66(Suppl. I): 85-92 (1982).

19. S. R. Jolly, W. J. Kane, M. B. Bailie, G. D. Abrams, and B. $R$. Lucchesi. Canine myocardial reperfusion injury. its reduction by the combined administration of superoxide dismutase and catalase. Circ. Res. 54: 277-285 (1984).

20. J. L. Romson, L. R. Bush, S. R. Jolly, and B. R. Lucchesi. Cardioprotective effects of ibuprofen in experimental regional and global myocardial ischemia. J. Cardiovasc. Pharmacol. 4: 187-196 (1982)

21. M. C. Fishbein, S. Meerbaum, J. Rit. U. Lando. K. Kanmatsuse. J. C. Mercier. E. Corday, and W. Ganz. Early phase acute myocardial infarct size quantification: Validation of the triphenyltetrazolium chloride tissue enzyme staining technique. Am. Heart J. 101: 593-600 (1981).

22. J. L. Romson. B. G. Hook. V. H. Rigot. M. A. Schork. D. P. Swanson. and B. R. Lucchesi. The effect of ibuprofen on accumulation of indium-11I labeled platelets and leukocytes in experimental myocardial infarction. Circulation 66: 1002-1011 (1982).

23. R. Snyderman and E. J. Goetzl. Molecular and cellular mechanism of leukocyte chemotaxis. Science 213: 830-837 (1981).

24. R. A. Lewis and K. F. Austen. The biologically active leukotrienes. J. Clin. Invest. 73: 889-897 (1984).

25. S. R. Jolly and B. R. Lucchesi. Effect of BW755C in an occlusion-reperfusion model of ischemic myocardial injury. Am. Heari J. 106: 8-13 (1983).

26. M. J. Shea. J. J. Murtagh, S. R. Jolly, G. D. Abrams. B. Pitt. and $B$. R. Lucchesi. Beneficial effects of nafazatrom on ischemic reperfused myocardium. Eur. J. Pharmacol. 102: 63-70 (1984).

27. M. Bednar. B. Smith, and K. Mullane. Nafazatrom-induced inhibition of neutrophil function mediates salvage of ischemic myocardiu. Fed. Proc. 43: 612 abstr. (1984).

28. T. Sacks. C. F. Moldow. P. R. Craddock. T. K. Bowers. and H. S. Jacob. Oxygen radicals mediate endothelial cell damage by complement-stimulated granulocytes. J. Clin. Imest. 61: 11611167 (1978).

29. K. P. Burton. J. M. McCord. and G. Ghai. Myocardial alterations due to free-radical generation. Am. J. Physiol. 246: H776H783 (1984).

30. M. L. Hess, E. Okabe. P. Ash. and H. A. Kontos. Free radical mediation of the effects of acidosis on calcium transport by cardiac sarcoplasmic reticulum in whole heart homogenates. Cardiovasi. Res. 18: 149-157 (1984).

31. W. F. Petrone. D. K. English. K. Wong. and J. M. McCord. Free radicals and inflammation: Superoxide-dependent activation of a neutrophil chemotactic factor in plasma. Proc. Natl. Acad. Sci. 77: 1159-1163 (1980).

32. B. A. Freeman and J. D. Crapo. Free radicals and tissuc injury Lab. Invest. 47: 412-426 (1982)

33. H. Otani. H. Tanaka, T. Inoue, M. Umemoto. K. Omoto. K. Tanaka, T. Sato. T. Osako. A. Masuda. A. Nonoyama. and T. Kagawa. In vitro study on contribution of oxidative metabolism 
of isolated rabbit heart mitochondria to myocardial reperfusion injury. Circ. Res. 55: 168-175 (1984).

34. K. R. Chien, A: Han, A. Sen, L. M. Buja, and J. T. Willerson. Accumulation of unesterified arachidonic acid in ischemic canine myocardium. Circ. Res. 54: 313-322 (1984).

35. R. W. Egan, P. H. Gale, and F. A. Kuehl. Reduction of hydroperoxides in the prostaglandin biosynthetic pathway by a microsomal peroxidase. J. Biol. Chem. 254: 3295-3302 (1979).

36. R. B. Jennings, K. A. Reimer, M. L. Hill, and S. E. Mayer. Total ischemia in dog hearts, in vitro. Circ. Res. 49: 892-900 (1981).

37. J. V. Bannister, W. H. Bannister, H. A. O. Hill, and P. I. Thornalley. Enhanced production of hydroxyl radicals by the $x a n t h i n e-x a n t h i n e$ oxidase reaction in the presence of lactoferrin. Biochim. Biophys. Acta 715: 116-120 (1982).

38. S. J. Klebanoff. Oxygen metabolism and the toxic properties of phagocytes. Ann. Int. Med. 93: 480-489 (1980).

39. S. J. Weiss and A. F. LoBuglio. Phagocyte-generated oxygen metabolites and cellular injury. Lab. Invest. 47: 5-18 (1982).

40. P. A. Ward, G. O. Till, R. Kunkel, and C. Beauchamp. Evidence for role of hydroxyl radical in complement and neutrophil-dependent tissue injury. J. Clin. Invest. 72: 789-801 (1983).

41. S. J. Weiss, M. B. Lambert, and S. T. Test. Long-lived oxidants generated by human neutrophils: characterization and bioactivity. Science 222: 625-628 (1983).

42. P. Biemond, H. G. VanEijk, A. J. G. Swaak, and J. F. Koster. Iron mobilization from ferritin by superoxide derived from stimulated polymorphonuclear leukocytes. J. Clin. Invest. 73: 15761579 (1984).

43. H. D. Perez, B. B. Weksler, and I. M. Goldstein. Generation of a chemotactic lipid from arachidonic acid by exposure to a superoxide-generating system. Inflammation 4: 313-328 (1980).

44. L. Parente. Study on the effect of superoxide dismutase on archidonic acid metabolism. Prostaglandins 23: 725-730 (1982).

45. J. M. Harlan and K. S. Calahan. Role of hydrogen peroxide in the neutrophil-mediated release of prostacyclin from cultured endothelial cells. J. Clin. Invest. 74: 442-448 (1984).
46. R. O. Bonow, L. L. Lipson. F. H. Sheehan. N. L. Capurro. J. M. Isner, W. C. Roberts, R. E. Goldstein, and S. E. Epstein. Lack of effect of aspirin on myocardial infarct size in the dog. Am. J. Cardiol. 47: 258-264.

47. P. J. Flynn, W. K. Becker, G. M. Vercellotti. D. J. Weisdorf. P. R. Craddock, D. E. Hammerschmidt, R. C. Lillehei, and $H$ $S$. Jacob. Ibuprofen inhibits granulocyte responses to inflammatory mediators. Inflammation 8: 33-44.

48. J. A. Melin and L. C. Becker. Salvage of ischemic myocardium by prostacyclin during experimental myocardial infarction. $J$. Am. Coll. Cardiol. 2: 279-286 (1983).

49. J. C. Fantone and D. A. Kinnes. Prostaglandin $E_{1}$ and prostaglandin $I_{2}$ modulation of superoxide production by human neutrophils. Biochem. Biophvs. Res. Comm. 113: 506-512 (1983).

50. R. A. DeWall, K. A. Vasko, E. L. Stanley, and P. Kazdi Responses of the ischemic myocardium to allopurinol. Am. Heart J. 82: 362-370 (1971).

51. T. J. Gardner, J. R. Stewart, A. S. Casale. J. M. Downey, and D. E. Chambers. Reduction of myocardial ischemic injury with oxygen-derived free radical scavengers. Surgery 94: 423-427 (1983).

52. G. J. Magovern, S. F. Bolling, A. S. Casale, B. H. Bulkley. and T. J. Gardner. The mechanism of mannitol in reducing ischemic injury: Hyperosmolarity or hydroxyl scavenger'? Circulation 70(Suppl. I): I-91-I-95 (1984).

53. A. Janoff and $H$. Carp. Proteases, antiproteases, and oxidants Pathways of tissue injury during inflammation. In: Current Topics in Inflammation and Infection (G. Majno, R. S. Cotran, and N. Kaufman, eds.), pp. 62-82, Williams and Wilkins, Baltimore (1982).

54. R. A. Greenwald and W. W. Moy. Effect of oxygen derived free radicals on hyaluronic acid. Arthritis Rheum. 23: 455-463 (1980).

55. J. M. McCord. Free radicals and inflammation: Protection of synovial fluid by superoxide dismutase. Science 185: 529-531 (1974)

56. G. L. Laffel and E. Bruanwald. Thrombolytic therapy: A new strategy for the treatment of acute myocardial infarction. $N$ Engl. J. Med. 311: 710-717, 770-776 (1984). 